\title{
Estimation of effective hydraulic parameters in heterogeneous soils at field scale
}

\author{
Jianbin Lai ${ }^{\mathrm{a}, \mathrm{b}}$, Li Ren ${ }^{\mathrm{b}, *}$ \\ a Key Laboratory of Ecosystem Network Observation and Modeling, Institute of Geographic Sciences and Natural Resources Research, Chinese Academy of Sciences, Beijing 100101, China \\ b Department of Soil and Water Sciences, Key Laboratory of Plant-Soil Interactions, Ministry of Education, China Agricultural University, Beijing 100193, China
}

\section{A R T I C L E I N F O}

\section{Article history:}

Received 24 May 2015

Received in revised form 9 September 2015

Accepted 16 September 2015

Available online 24 October 2015

\section{Keywords:}

Soil hydraulic parameter

Equivalent soil column

Inverse modeling

HYDRUS-1D

\begin{abstract}
A B S T R A C T
Determination of soil hydraulic parameters at field scale is of great importance for modeling soil water dynamics and for agricultural water management practice. The parameter regionalization has been a hot topic for many decades in soil science and hydropedology. Based on the statistical description and spatial structure of the soil physical and hydraulic properties measured via soil sampling in the field, three inverse modeling approaches had been proposed to obtain the effective hydraulic parameters. The validity and effectiveness of the three approaches had been discussed by designing four simulation scenarios (a 'fine scale solution' plus the three upscaling approaches). For each inverse modeling, the soil water distribution along the profiles and their dynamics during seven growing seasons (from the year of 2000 to 2006) in the study area had been simulated through the combined use of HYDRUS-1D and PEST. Results demonstrated that the effective soil hydraulic parameters derived from all the three approaches were comparable and fairly close to the 'fine scale solution'. Although, statistics of the hydraulic parameters indicated that the median of $K_{\mathrm{s}}$ of first soil layer, as compared to that of other layers, was most closest to the effective $K_{s}$ values that were obtained through the three upscaling approaches; while the median of $\theta_{\mathrm{s}}$ values for the top three layers was close to the effective $\theta_{\mathrm{s}}$ values in scenario 2 and scenario 3 , but fairly smaller than that in scenario 4 . The soil water dynamics were not sensitive to the residual soil water content $\left(\theta_{\mathrm{r}}\right)$, even though the $\theta_{\mathrm{r}}$ showed quite different distribution pattern from that of $K_{\mathrm{s}}$ and $\theta_{\mathrm{s}}$. In conclusion, the practice of combining the PEST with the HYDRUS-1D provided an effective and reasonable method to inversely determine the effective hydraulic parameters of the equivalent soil profile in the field.
\end{abstract}

(c) 2015 Elsevier B.V. All rights reserved.

\section{Introduction}

Soil hydraulic properties are by far the most important land surface parameters to govern the partitioning of soil water fluxes at a range of spatial scales (Mohanty, 2013). A very good knowledge of the "withinfield' spatial variability of soil properties and water distribution and its temporal dynamics is of prime importance to estimate field areal soil water productivity (Jhorar et al., 2002). However, an obstacle to the practical application of soil hydraulic properties at the field, catchment, or regional scale is the difficulty of quantifying the "effective" soil hydraulic functions (Feddes et al., 1993; Ahuja et al., 2010). It is intensified by the fact that soil water movement is mainly controlled by the soil properties which are characterized by a small measurement support. Therefore, accurate estimate of the soil hydraulic parameters at the application scale of interest is critically important to the models simulating flow and transport through the vadose zone (Vrugt et al., 2008).

\footnotetext{
* Corresponding author at: Department of Soil and Water Sciences, China Agricultural University, No. 2 Yuanmingyuan West Road, Beijing 100193, China

E-mail address: renl@mx.cei.gov.cn (L. Ren).
}

A number of field and laboratory measurement techniques have been developed (Klute and Dirksen, 1986) and research has continued with the objective of improving the measurement of hydraulic parameters and analytical techniques (Kosugi, 1996; Vachaud and Dane, 2002). However, for practical consideration, general experimental procedures are time consuming, costly; in addition, most of these procedures have focused on relatively small soil cores or support area (Arya and Heitman, 2010). Unfortunately, many contributions to the soil science and hydrology literature have demonstrated an inability of these laboratory-scale measurements on small soil cores to accurately characterize flow and transport processes at larger spatial scales. Thus, it necessitates the development of alternative methods to derive the soil hydraulic properties at the application scale of model. As a result, indirect methods to obtain soil hydraulic parameters have gained popularity (Schaap and Leij, 2000; Priesack and Durner, 2006; Rucker, 2010).

Geologic formations are heterogeneous at various length scales. Such a critical length scale marks the transition towards hydraulic non-equilibrium where water content and water potential are not directly coupled anymore by a static retention characteristic. At this point the application of Richards' equation starts to be doubtable (Vogel et al., 2010; Szymkiewicz et al., 2012). An alternative approach is to 
predict the mean flow and transport behavior at the field scale by defining an equivalent homogeneous medium with upscaled (effective or macroscopic) flow and transport properties (Yeh, 1998). However, to represent a heterogeneous medium by its homogeneous equivalent, one needs to estimate the effective flow and transport properties that represent this equivalent homogeneous medium.

There are different approaches for scaling of soil hydraulic properties and soil water processes in heterogeneous porous media (Vereecken et al., 2007). The strengths and limitations of those methods have been previously discussed (Sadeghi et al., 2014). Among many of those approaches, inverse modeling provided a useful tool to estimate the effective parameters of an equivalent soil column at different spatial scales. In Chrysikopoulos (1995), effective parameters for flow in saturated porous media were obtained by considering both periodic and stationary porous medium properties. The results showed that the effective hydraulic conductivity is equal to its volume average plus a term expressing the effect of the locally variable hydraulic conductivity. Hughson and Yeh (2000) presented an inverse model using a successive linear estimator approach for estimating unsaturated hydraulic parameters during transient, three-dimensional, variably saturated flow. Khaleel et al. (2002) used stochastic theory-based analytical formulas and numerical Monte Carlo simulations to obtain upscaled (effective) flow and transport properties to represent a heterogeneous unsaturated medium. More recently, Erdal et al. (2012) investigated the reliability of inverse modeling for finding the effective hydraulic parameters in three different heterogeneity structures (random, periodic and layered). In Sadeghi et al. (2014), a new solution for prediction of the effective unsaturated hydraulic conductivity of layered soils was presented and evaluated. Shafiei et al. (2014) demonstrated that simulation uncertainty in soil moisture at field scale is relative small and a good model performance was obtained. The typically used effective parameters were assumed that the equivalent hydraulic properties still follow the same form of hydraulic property functions as the local ones did, but have the parameters in the hydraulic property functions replaced by the so-called effective parameters so that the hydraulic parameters can be used in heterogeneous soil and large-scale applications (Desbarats, 1998; Zhu and Mohanty, 2003; Zhu, 2008). However, additional work is needed to determine effective hydraulic parameters across spatial scales, develop subsurface soil property databases, and implement the approach on spatially correlated pixels (Corwin et al., 2006). Numerical simulation models, which were capable to validate the effective hydraulic parameters of the equivalent homogeneous medium, can be used to screen a promising upscaling practice that warrants future field studies among various upscaling practices. Therefore, in this study, three inverse modeling approaches were proposed to obtain effective hydraulic parameters of equivalent soil columns from field sampling data.
The objective of this study was to explore the validity of these three inverse modeling approaches. Thus, field sampling and numerical experiments were designed to simulate the water movement dynamics at field scale.

\section{Materials and methods}

\subsection{Study site description}

The field experiments were conducted at the Xuebai Experimental Station ( $103^{\circ} 03^{\prime} \mathrm{E}, 38^{\circ} 54^{\prime} \mathrm{N}, 1324 \mathrm{~m}$ a.s.l.) of Minqin Agricultural Extension Center of Gansu province, north-west China from July to August in 2005 (Fig. 1). The experimental site was located in Minqin oasis, which is surrounded by Badanjilin desert at north and west sides and Tengger desert at east. It is a large and plain area and far from the highland or hills. The soil type is classified as the anthropogenic alluvial soil, and loamy fine sand and silt loams are the predominant textures for the surface soil (Minqin Water Conservancy Bureau, 1996). The climate is classified as a typical continental temperate semi-arid climate with mean annual precipitation of $110 \mathrm{~mm}$, which largely comes during the summer and fall months. The annual potential evaporation is about $2600 \mathrm{~mm}$. The spring wheat (Triticum aestivum L.) was planted in the experimental plot.

\subsection{Soil sampling and data collection}

Totally three groups of sampling were conducted within the $120 \mathrm{~m} \times 120 \mathrm{~m}$ experimental plot (Fig. 1). The first group consisted of 30 (5-row $\times 6$-line) sampling sites which separated by an interval of $20 \mathrm{~m}$. At each site, soil samples have been collected at eight layers $(0-20 \mathrm{~cm}, 20-40 \mathrm{~cm}$, and so on, down to $160 \mathrm{~cm})$. The second group consisted of 169 (13-row $\times 13$-line) sampling sites which separated by an interval of $10 \mathrm{~m}$. At each site, soil samples have been collected at two layers $(0-10 \mathrm{~cm}$ and $10-20 \mathrm{~cm})$. These samples were used to investigate the spatial structure of soil properties in the experimental plot. All these two groups of soil samples were collected by means of auger and then the soil particle size distribution had been measured using processed air-dry soil. Field measured soil texture data (Fig. 2) were used to derive the effective parameters of all 30 so-called homogeneous 'simulation units'. For the third soil sampling group, seven soil profiles of $200 \mathrm{~cm}$ in depth had been dug to detect the soil layer and to measure soil bulk density of each layer. The determined soil layer was shown in Fig. 3.

In addition, $338(2 \times 169)$ undisturbed soil samples were taken at the 169 sampling sites by using core method. Firstly, a flat sampling

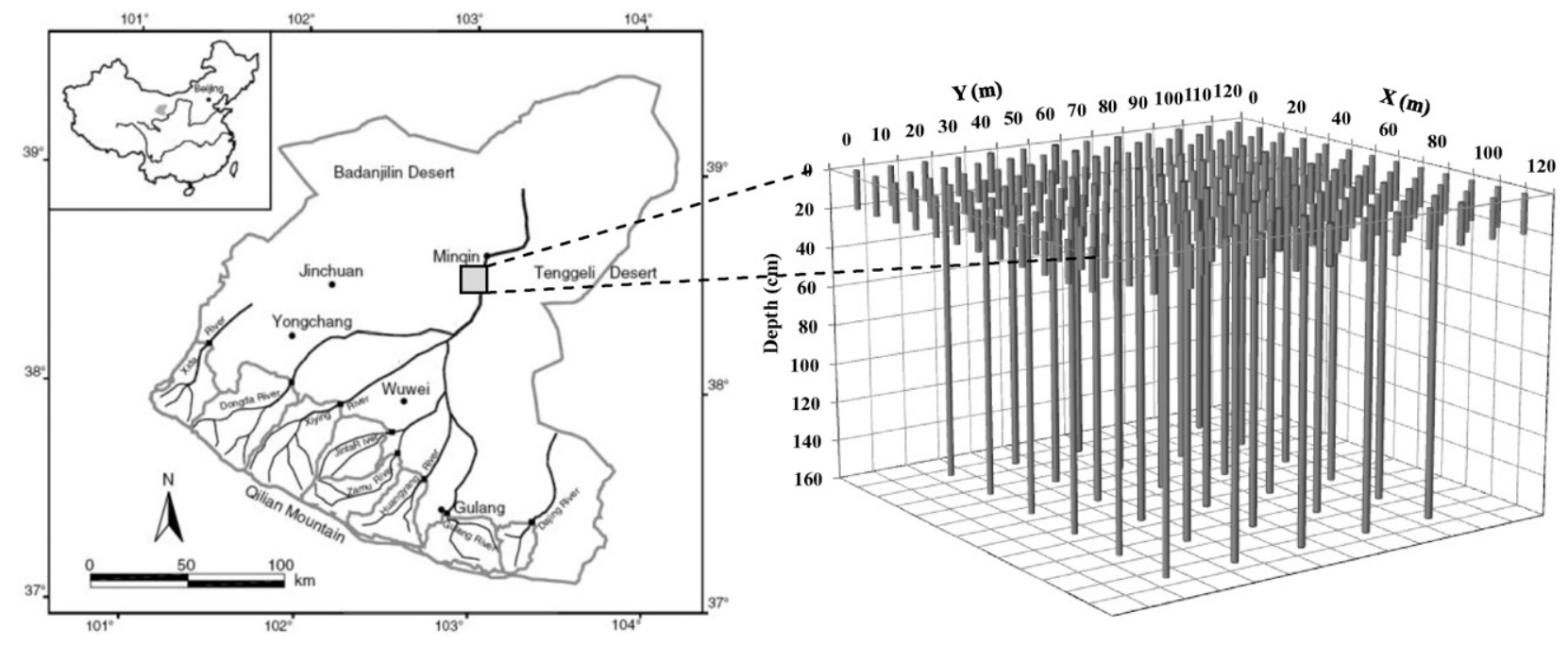

Fig. 1. The location and depth for soil sampling in an experimental plot located in the Shiyang river basin (shaded in the inset map of China). 


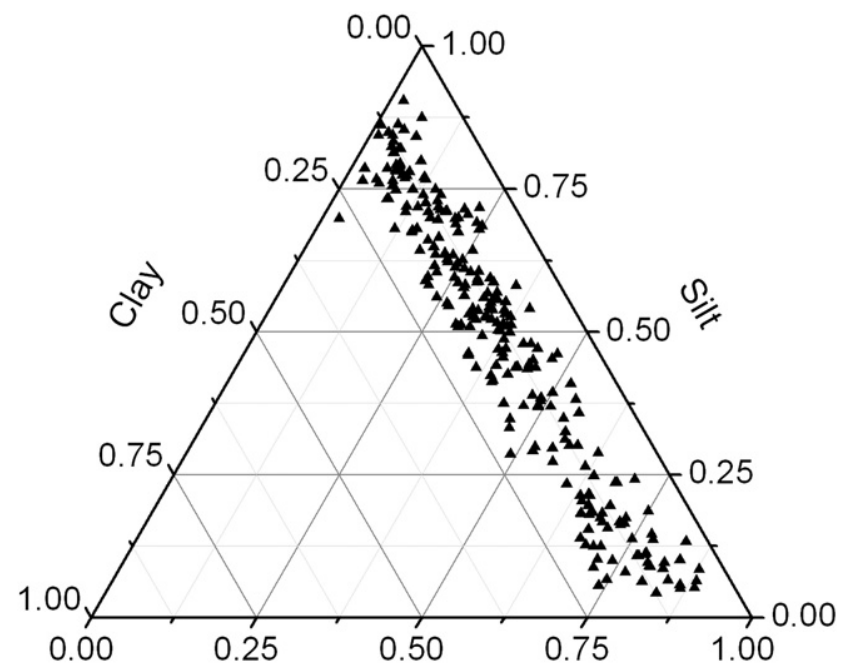

Sand

Fig. 2. Soil texture triangular diagram of 30 soil profiles.

platform at the depths of $10 \mathrm{~cm}$ and $20 \mathrm{~cm}$ were prepared with a spade, then standard sharpened steel $100-\mathrm{cm}^{3}$ Kopecky rings were driven into the soil using a dedicated ring holder. In hard layer, a percussion-free hammer was applied for hammering the ring holder with a minimum of vibration into the soil. Then, the soil-filled cylinder was carefully removed from the ring holder and the oversized soil was trimmed flush using a sharp knife. Samples with stones, charcoal or roots larger than $2 \mathrm{~mm}$ in diameter were rejected and re-sampled in the same horizon. The samples were transported and placed in the oven at $105{ }^{\circ} \mathrm{C}$ for $24 \mathrm{~h}$, and then weighed to determine the oven-dry weight of the sample. This was allowed to calculate soil bulk density $\left(\rho_{\mathrm{b}}\right)$. Bulk densities varied from 1.23 to $1.72 \mathrm{Mg} \mathrm{m}^{-3}$.

The particle size distributions were determined on disturbed soil samples using pipette method (Gee and Bauder, 1986). To compute the transient soil water flow, HYDRUS-1D requires the soil hydraulic functions $\theta(\mathrm{h})$ and $K(\theta)$. Direct measurement of these soil hydraulic parameters is difficult, especially at regional scale. As an alternative, Rosetta (Ver 1.1) pedotransfer functions (Schaap, 1999) were applied, which relate $\theta(\mathrm{h})$ and $K(\theta)$ to the easy available soil information: soil texture and bulk density. Therefore, soil hydraulic parameters, such as soil saturated hydraulic conductivity $\left(K_{s}\right)$, saturated water content $\left(\theta_{s}\right)$, residual water content $\left(\theta_{r}\right)$, and the shape factors $\alpha$ and $n$, were estimated by means of pedotransfer functions in present study. The statistics of soil hydraulic parameters in van Genuchten (1980) model (VG) of 30 soil profiles at each layer are given in Table 1.

For the simulation period, daily meteorological data including air temperature, daily rainfall, wind speed, relative humidity, and solar radiation were measured in a weather station in the vicinity of the experimental field.

\subsection{Geostatistics analysis of soil physico-hydraulic parameters}

Soil is a spatially heterogeneous and structured porous media. The semi-variogram is used to analyze the spatial structure of soil properties and can be described as:

$\gamma(h)=\frac{1}{2 N(h)} \sum_{i=1}^{N(h)}\left[Z\left(x_{i}\right)-Z\left(x_{i}+h\right)\right]^{2}$

Where $\gamma(h)$ is semi-variogram function; $h$ is the lag (i.e. the distance between two sampling sites); $N(h)$ is the pair numbers of sampling sites with a lag of $h ; Z(x)$ is measured values of the soil property.

The spatial relationships of soil clay, silt, and sand content in upper $(0-10 \mathrm{~cm})$ and lower $(10-20 \mathrm{~cm})$ layers at 169 sampling sites were calculated by using the Geo-analysis software (Zhang, 2004). The variogram model type, range, nugget, and sill of all the soil properties were listed in the table (Table 2). The results indicated that the variogram of soil sand content and silt content can be fitted with linear model (Table 2); while a spherical model was suitable for the variogram of soil clay content. The range is $40.5 \mathrm{~m}$ and $52.15 \mathrm{~m}$ for the variogram of soil clay content in the layer of $0-10 \mathrm{~cm}$ and $10-20 \mathrm{~cm}$, respectively.

Moreover, the spatial co-relationship of soil hydraulic conductivity $K_{\mathrm{s}}$ at 169 sites in $0-20 \mathrm{~cm}$, which were measured through Guelph infiltrometer, was calculated. The results indicated that it is strongly correlated for soil saturated hydraulic conductivity $K_{s}$; and the variogram of saturated hydraulic conductivity $K_{\mathrm{s}}$ can be fitted with spherical model with a range of $61.42 \mathrm{~m}$.

\subsection{Numerical simulation and model description}

\subsubsection{Simulation scenarios}

Four simulating scenarios were designed in this study and are described as follows: (1) Fine scale solution (scenario 1, S1): the
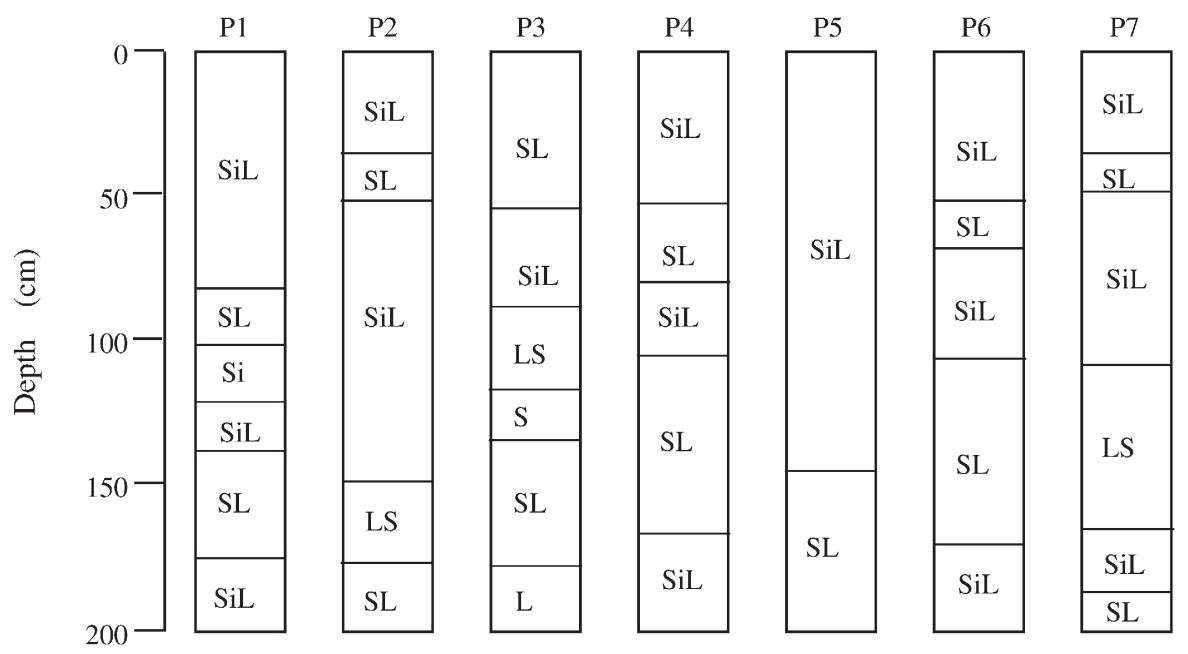

Fig. 3. Texture information of the seven soil profiles (P1 to P7). Note: S stand for sand or sandy; Si for silt or silty; C for clay; L for loam. 
Table 1

The statistics of soil hydraulic parameters (estimated from Rosetta) in VG model of 30 soil profiles.

\begin{tabular}{|c|c|c|c|c|c|c|c|c|c|}
\hline Parameters & & Min. & Max. & Mean & S.D. & $\mathrm{CV}$ & Skewness & Kurtosis & $\mathrm{K}-\mathrm{S}$ \\
\hline \multirow{5}{*}{ Layer 1} & $\theta_{\mathrm{r}}$ & 0.0360 & 0.0641 & 0.0511 & 0.0088 & 0.1720 & -0.1818 & -1.2187 & 0.4509 \\
\hline & $\theta_{\mathrm{s}}$ & 0.3864 & 0.4280 & 0.4086 & 0.0112 & 0.0274 & -0.4427 & -0.8550 & 0.4161 \\
\hline & $K_{\mathrm{s}}$ & 12.6953 & 61.7750 & 30.0580 & 12.2931 & 0.4090 & 0.7667 & 0.2675 & 0.6183 \\
\hline & $\alpha$ & 0.0044 & 0.0335 & 0.0092 & 0.0070 & 0.7700 & 1.9626 & 3.7511 & 0.0031 \\
\hline & $\mathrm{n}$ & 1.3934 & 1.6838 & 1.5782 & 0.0967 & 0.0613 & -0.8488 & -0.7570 & 0.0377 \\
\hline \multirow{5}{*}{ Layer 2} & $\theta_{\mathrm{r}}$ & 0.0437 & 0.0864 & 0.0543 & 0.0085 & 0.1561 & 2.0801 & 6.3398 & 0.2752 \\
\hline & $\theta_{\mathrm{s}}$ & 0.3756 & 0.4719 & 0.4156 & 0.0278 & 0.0668 & 0.4632 & -0.7915 & 0.9031 \\
\hline & $K_{\mathrm{s}}$ & 9.5875 & 113.9660 & 31.1192 & 19.6408 & 0.6311 & 2.8904 & 10.6513 & 0.0949 \\
\hline & $\alpha$ & 0.0043 & 0.0337 & 0.0106 & 0.0095 & 0.8935 & 1.6072 & 1.1385 & 0.0211 \\
\hline & $\mathrm{n}$ & 1.3604 & 1.8095 & 1.5981 & 0.1170 & 0.0732 & -0.5336 & -0.6066 & 0.5047 \\
\hline \multirow{5}{*}{ Layer 3} & $\theta_{\mathrm{r}}$ & 0.0382 & 0.0703 & 0.0554 & 0.0075 & 0.1361 & -0.0960 & -0.1832 & 0.9546 \\
\hline & $\theta_{\mathrm{s}}$ & 0.3732 & 0.4629 & 0.4165 & 0.0225 & 0.0540 & 0.4163 & -0.2088 & 0.7176 \\
\hline & $K_{\mathrm{s}}$ & 11.2031 & 55.9889 & 27.4666 & 11.1217 & 0.4049 & 0.8528 & 1.0699 & 0.7725 \\
\hline & $\alpha$ & 0.0043 & 0.0309 & 0.0090 & 0.0072 & 0.8060 & 2.0211 & 3.4972 & 0.0057 \\
\hline & $\mathrm{n}$ & 1.3880 & 1.7227 & 1.6031 & 0.0886 & 0.0553 & -0.7279 & -0.2177 & 0.5641 \\
\hline \multirow{5}{*}{ Layer 4} & $\theta_{\mathrm{r}}$ & 0.0359 & 0.0775 & 0.0554 & 0.0094 & 0.1690 & 0.2789 & 0.5857 & 0.9691 \\
\hline & $\theta_{\mathrm{s}}$ & 0.3744 & 0.4720 & 0.4154 & 0.0301 & 0.0725 & 0.5756 & -1.0201 & 0.2852 \\
\hline & $K_{\mathrm{s}}$ & 10.1100 & 98.4883 & 27.2176 & 16.1285 & 0.5926 & 3.0726 & 13.1117 & 0.2686 \\
\hline & $\alpha$ & 0.0043 & 0.0339 & 0.0119 & 0.0093 & 0.7835 & 1.2979 & 0.3158 & 0.1215 \\
\hline & $\mathrm{n}$ & 1.3555 & 1.7226 & 1.5679 & 0.1114 & 0.0710 & -0.2754 & -1.2256 & 0.5013 \\
\hline \multirow{5}{*}{ Layer 5} & $\theta_{\mathrm{r}}$ & 0.0436 & 0.0733 & 0.0595 & 0.0091 & 0.1521 & -0.2652 & -1.0943 & 0.6871 \\
\hline & $\theta_{\mathrm{s}}$ & 0.3763 & 0.5086 & 0.4364 & 0.0355 & 0.0813 & -0.2985 & -0.8049 & 0.4354 \\
\hline & $K_{\mathrm{s}}$ & 14.0608 & 251.4337 & 35.1440 & 43.4581 & 1.2366 & 4.5651 & 22.7526 & 0.0020 \\
\hline & $\alpha$ & 0.0043 & 0.0380 & 0.0107 & 0.0109 & 1.0191 & 1.8338 & 1.7178 & 0.0001 \\
\hline & $\mathrm{n}$ & 1.3773 & 2.3094 & 1.6433 & 0.1523 & 0.0927 & 2.6456 & 12.9962 & 0.0275 \\
\hline \multirow{5}{*}{ Layer 6} & $\theta_{\mathrm{r}}$ & 0.0480 & 0.0745 & 0.0598 & 0.0073 & 0.1228 & 0.0467 & -1.1052 & 0.6319 \\
\hline & $\theta_{\mathrm{s}}$ & 0.3713 & 0.4883 & 0.4290 & 0.0410 & 0.0956 & -0.0103 & -1.5107 & 0.5316 \\
\hline & $K_{\mathrm{s}}$ & 14.1545 & 160.8857 & 34.0385 & 29.6200 & 0.8702 & 3.1175 & 11.4287 & 0.0033 \\
\hline & $\alpha$ & 0.0044 & 0.0349 & 0.0136 & 0.0117 & 0.8661 & 0.9475 & -1.0186 & 0.0005 \\
\hline & $\mathrm{n}$ & 1.3776 & 1.9995 & 1.6141 & 0.1185 & 0.0734 & 0.2975 & 3.6902 & 0.1542 \\
\hline \multirow{5}{*}{ Layer 7} & $\theta_{\mathrm{r}}$ & 0.0343 & 0.0749 & 0.0555 & 0.0099 & 0.1776 & -0.1233 & -0.7217 & 0.8721 \\
\hline & $\theta_{\mathrm{s}}$ & 0.3750 & 0.4903 & 0.4158 & 0.0372 & 0.0894 & 0.6245 & -1.0323 & 0.1086 \\
\hline & $K_{\mathrm{s}}$ & 11.5151 & 249.7511 & 43.4304 & 49.8778 & 1.1485 & 3.1145 & 10.4027 & 0.0058 \\
\hline & $\alpha$ & 0.0044 & 0.0425 & 0.0184 & 0.0139 & 0.7526 & 0.2916 & -1.7098 & 0.0205 \\
\hline & $\mathrm{n}$ & 1.3658 & 2.2957 & 1.5979 & 0.2005 & 0.1255 & 1.5005 & 3.8584 & 0.1139 \\
\hline \multirow{5}{*}{ Layer 8} & $\theta_{\mathrm{r}}$ & 0.0425 & 0.0687 & 0.0531 & 0.0083 & 0.1559 & 0.7978 & -0.4660 & 0.4250 \\
\hline & $\theta_{\mathrm{s}}$ & 0.3715 & 0.4638 & 0.4008 & 0.0280 & 0.0698 & 1.0727 & -0.3911 & 0.0458 \\
\hline & $K_{\mathrm{s}}$ & 15.1805 & 242.5082 & 44.9748 & 48.2444 & 1.0727 & 3.0805 & 10.2701 & 0.0078 \\
\hline & $\alpha$ & 0.0045 & 0.0386 & 0.0210 & 0.0130 & 0.6200 & -0.1971 & -1.7823 & 0.1352 \\
\hline & $\mathrm{n}$ & 1.3701 & 2.3029 & 1.5644 & 0.2066 & 0.1321 & 1.8845 & 4.8523 & 0.3276 \\
\hline
\end{tabular}

simulation result of fine grid sampling (30 heterogeneous soil profiles) has been considered as the "fine scale solution" or "virtual reality" due to lack of field observations, then, the simulation results of other three scenarios have been compared with the "fine scale solution". (2) The vertically upscaling method (scenario $2, \mathrm{~S} 2$ ) was used to obtain 30 equivalent homogenous soil profiles with effective hydraulic parameters for 30 heterogeneous soil profiles by using PEST (Parameter ESTimation program) software package (Watermark Computing, 1994). (3) The inverse modeling upscale method (scenario 3, S3): based on the simulation outputs of scenario 2 , soil water content of 30 homogeneous soil profiles were averaged at each of eight depths and set as initial soil water content of an upscaled effective homogeneous soil column for the entire area. Then, the effective soil hydraulic parameters of this upscaled effective homogeneous soil column for entire area were obtained by using the PEST software package. (4) The block-Kriging upscale method (scenario 4, S4) was used firstly to integrate the soil hydraulic parameters of all the 30 effective soil profiles, which was obtained in scenario 2, to generate 9 sub-blocks of equivalent soil column by using the block-Kriging interpolation method, and then to obtain the effective soil hydraulic parameter of an upscaled effective homogeneous soil column for the entire area by means of arithmetic averaging.

Table 2

Summarization of the semi-variogram of topsoil properties.

\begin{tabular}{|c|c|c|c|c|c|}
\hline Soil layer & Parameters & Model & Nugget & Sill & Range (m) \\
\hline \multirow{6}{*}{$0-10 \mathrm{~cm}$} & Sand content (\%) & Linear without sill & 12.985 & - & - \\
\hline & Silt content $(\%)$ & Linear without sill & 23.376 & - & - \\
\hline & Clay content (\%) & Spherical & 0.12 & 0.255 & 40.5 \\
\hline & Bulk density $\left(\mathrm{g} / \mathrm{cm}^{3}\right)$ & Spherical & 0.0038 & 0.0069 & 42 \\
\hline & Saturated water content $\theta_{\mathrm{s}}$ & Spherical & 0.00036 & 0.00095 & 44.27 \\
\hline & Sand content (\%) & Linear without sill & 40.995 & - & - \\
\hline \multirow{4}{*}{$10-20 \mathrm{~cm}$} & Silt content $(\%)$ & Linear without sill & 42.911 & - & - \\
\hline & Clay content (\%) & Spherical & 3.1 & 16.2 & 52.15 \\
\hline & Bulk density & Spherical & 0.0025 & 0.0055 & 61.43 \\
\hline & Saturated water content $\theta_{\mathrm{s}}$ & Spherical & 0.00047 & 0.00115 & 56.4 \\
\hline $0-20 \mathrm{~cm}$ & Hydraulic conductivity $K_{\mathrm{s}}$ & Spherical & 49 & 138 & 61.42 \\
\hline
\end{tabular}



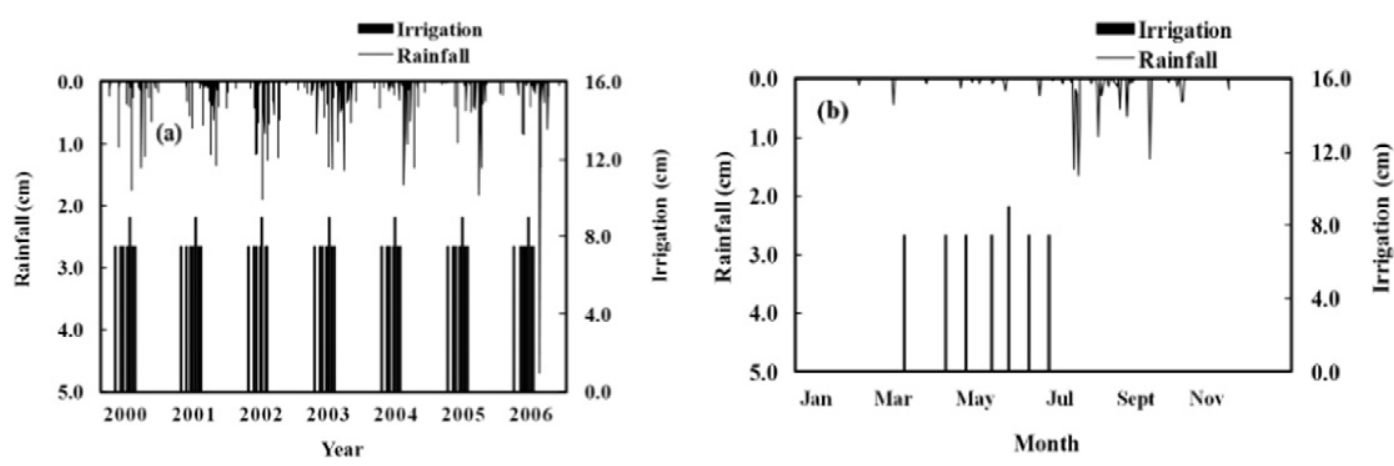

Fig. 4. The rainfall and irrigation events during (a) the whole simulation period; (b) 2004.

The simulation duration was seven continuous years from 2000 to 2006. The simulation period of 2000 to 2004 was used for determination of equivalent parameters. The boundary condition was in the natural meteorological condition. Then, we took the equivalent parameters as input of HYDRUS-1D; and the outputs of simulation (prediction) in 2006 were finally selected for comparison to verify the effective soil hydraulic parameters of equivalent homogeneous volume, which were obtained through three upscaling approaches (S2, S3 and S4).

\subsubsection{Model overview and parameters setting}

HYDRUS-1D (Šimůnek et al., 1998) is an integrated physical, biological and chemical process model and is widely used in modeling the soil water movement over and through the root zone (Sommer et al., 2003; Guber et al., 2006). Three components of HYDRUS-1D input were involved in present study, i.e. Soil properties, Meteorological data, and Water uptake by root. According to the simulation scheme of present study, all inputs are same for the four simulation scenarios except for the soil profile properties.

(1) Soil water movement module

In HYDRUS-1D, the governing equation in describing the onedimensional unsaturated soil water movement was a modified Richards' equation

$\frac{\partial \theta}{\partial t}=\frac{\partial}{\partial z}\left[K\left(\frac{\partial h}{\partial z}+1\right)\right]-S$

Where $\theta$ is volumetric soil moisture $\left[\mathrm{L}^{3} \mathrm{~L}^{-3}\right], h$ is water pressure head $[\mathrm{L}], t$ is time $[\mathrm{T}], z$ is the spatial coordinate $[\mathrm{L}]$ (positive upward), $S$ is the sink term indicating the effect of root water uptake $\left[\mathrm{T}^{-1}\right], K$ is the soil hydraulic conductivity function $\left[\mathrm{L} \mathrm{T}^{-1}\right]$.

Initial condition:

$h(z, t)=h_{i}(z) \quad z \geq 0 ; \quad t=0$

Where, $h_{\mathrm{i}}$ is total soil water pressure, and is a function of the depth $z$.

In our study, there was no runoff due to the low rain intensity and sandy soil texture, therefore the upper boundary condition was set as:

$-K\left(\frac{\partial h}{\partial z}+1\right)=q_{0}(t) \quad z=0, t>0$

Where, $q_{0}$ is the net infiltration rate (i.e. the difference between the rain intensity and evaporation rate).

A free drainage condition was adopted in lower boundary:

$\frac{\partial h}{\partial z}=0 \quad z=L, \quad t>0$

Where $L$ is the depth from the surface to bottom of flow domain, specifically, $L=160 \mathrm{~cm}$ in this study.

The water flow due to thermal and solute gradients did not take into account in this study.

(2) Root water uptake module

The sink term, $S$, is defined as the volume of water removed from a unit volume of soil per unit time due to water uptake by plant. Feddes et al. (1978) defined $S$ as:

$S(h)=\beta(h) S_{p}$

Where, $\beta(h)$ is the water stress response function relating to rootwater uptake, $S_{p}$ is potential water uptake rate $\left[\mathrm{T}^{-1}\right]$. By introducing a non-uniform distribution of the potential water uptake rate over a root zone of arbitrary shape, $S_{p}$ is described as:

$S_{p}=b(z) T_{p}$

Where, $T_{\mathrm{p}}$ is the potential transpiration rate $\left[\mathrm{L} \mathrm{T}^{-1}\right], b(\mathrm{z})$ is the normalized water uptake distribution $\left[\mathrm{L}^{-1}\right]$.

The wheat root in Minqin is generally distributed within a depth of $0-50 \mathrm{~cm}$, and the maximum root depth could be downward to $80 \mathrm{~cm}$. Therefore, a linearly decreasing root distribution function and root depth of $80 \mathrm{~cm}$ along the profile were assumed in this study. The parameters in Wesseling (1991) for the root water uptake of wheat were selected.

(3) The calculation of evapotranspiration

Table 3

The growing stage and irrigation scheme for spring wheat.

\begin{tabular}{|c|c|c|c|c|c|c|c|c|}
\hline Growing stage & Sowing & Seedling & Tillering & Panicle & Tasselling & Milking & Harvest & Total growing season \\
\hline Start date $(\mathrm{dd} / \mathrm{mm})$ & $21 / 3$ & $21 / 3$ & $29 / 4$ & $12 / 5$ & $1 / 6$ & $13 / 6$ & $16 / 7$ & $21 / 3-16 / 7$ \\
\hline Days needed $(\mathrm{d})$ & & 40 & 13 & 20 & 12 & 33 & & 118 \\
\hline Irrigation amount $(\mathrm{cm})$ & 7.5 & 7.5 & 7.5 & 7.5 & 9 & 7.5 & 7.5 & 54.0 \\
\hline Irrigation date $(\mathrm{dd} / \mathrm{mm})$ & $20 / 3$ & $20 / 4$ & $5 / 5$ & $25 / 5$ & $5 / 6$ & $20 / 6$ & $5 / 7$ & \\
\hline
\end{tabular}




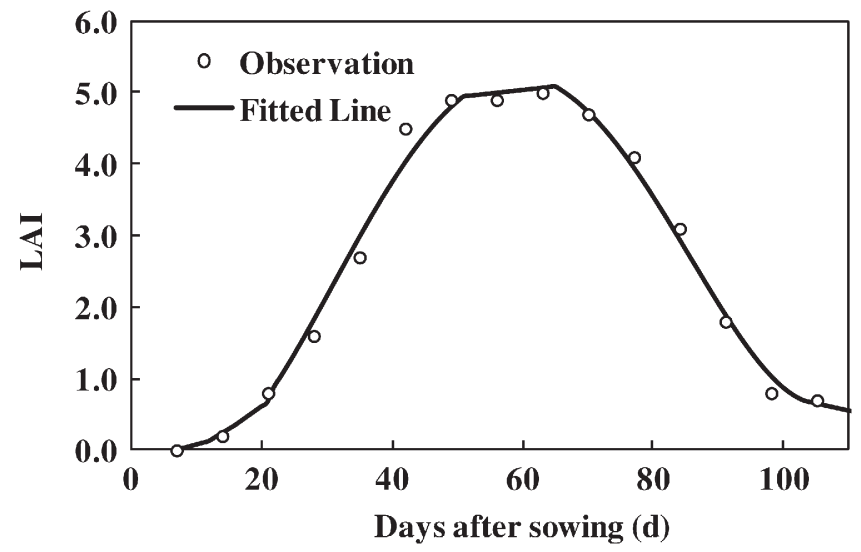

Fig. 5. The variation of LAI during the growing stage of spring wheat.

The upper boundary condition is determined by the potential evapotranspiration, and the rainfall and irrigation fluxes. The rainfall and irrigation events during the simulation period are shown in the figures and table (Fig. 4, and Table 3). In this study, the FAO 56 recommended Penman-Monteith equation was used to estimate the reference evapotranspiration $E T_{0}$ (Allen et al., 1998). The values of parameters or constant provided in the Liu et al. (1997) were adopted in this study. Assuming the surface resistance is $70 \mathrm{~s} \mathrm{~m}^{-1}$ and is a constant, ground reflection is 0.23 .

$E T_{0}=\frac{0.408 \times \Delta R_{n}+\gamma \times 900 \times U_{2} \cdot\left(e_{s}-e_{a}\right) /\left(T_{\text {mean }}+273\right)}{\Delta+\gamma \cdot\left(1+0.34 \times U_{2}\right)}$

where,

$R_{n}=0.77 \times R_{s}-\sigma \times\left(1.35 \times R_{s} / R_{s o}-0.35\right) \cdot\left(0.34-0.14 \times \sqrt{e_{a}}\right)\left(T_{\max , k}^{4}+T_{\min , k}^{4}\right) / 2$

$R_{s}=(a+b \cdot n / N) \cdot R_{a}$

$R_{S} / R_{S o}=(0.25+0.5 \times n / N) /[0.75+2 \times($ Altitude $) / 100000]$

$\Delta=\frac{4098 \times e_{a}}{(T+237.3)^{2}}$

$e_{a}(T)=0.618 \times \exp \left(\frac{17.27 \times T}{T+237.3}\right)$

The variables in Eqs. (8)-(13) are defined as follows:

$E T_{0}$ is the reference evapotranspiration $\left(\mathrm{mm} \mathrm{d}^{-1}\right) ; R_{n}$ is net radiation at the crop surface $\left(\mathrm{MJ} \mathrm{m}^{-2} \mathrm{~d}^{-1}\right) ; e_{s}$ and $e_{a}$ are saturation and actual vapor pressure, respectively $(\mathrm{kPa}) ; \Delta$ is slope vapor pressure curve $\left(\mathrm{kPa}{ }^{\circ} \mathrm{C}^{-1}\right) ; \gamma$ psychometric constant $\left(\mathrm{kPa}{ }^{\circ} \mathrm{C}^{-1}\right) ; U_{2}$ is wind speed at height of $2 \mathrm{~m}\left(\mathrm{~m} \mathrm{~s}^{-1}\right) ; R_{s}$ is short wave radiation at surface
$\left(\mathrm{MJ} \mathrm{m} \mathrm{m}^{-2} \mathrm{~d}^{-1}\right) ; R_{a}$ is solar radiation $\left(\mathrm{MJ} \mathrm{m}^{-2} \mathrm{~d}^{-1}\right) ; n$ and $N$ are the actual and theoretical sunshine hours, respectively (h); $T_{\max , k}$ and $T_{\min , k}$ are daily maximum and minimum temperatures, respectively $(\mathrm{K}) ; T_{\text {mean }}$ is daily mean temperature $\left({ }^{\circ} \mathrm{C}\right) ; \sigma$ is Stefan-Boltzmann's constant $\left(4.903 \times 10^{-9} \mathrm{MJ} \mathrm{K}^{-4} \mathrm{~m}^{-2} \mathrm{~d}^{-1}\right) ; a=0.25, b=0.5$; Altitude is the elevation above sea of the monitoring station $(\mathrm{m})$

In field conditions where crops partly cover the soil, the $E T_{0}$ is partitioned into the potential soil evaporation $E_{s p}\left[\mathrm{~L} \mathrm{~T}^{-1}\right]$ and the potential crop transpiration $T_{p}\left[\mathrm{~L} \mathrm{~T}^{-1}\right]$ using the leaf area index (LAI) as a function of crop development stage (Belmans et al., 1983). According to the formulation presented in Braud et al. (2005) and Huygen et al. (1997),

$E_{s p}=E T_{0} \cdot \exp (-\lambda \cdot L A I)$

$T_{p}=E T_{0}-E_{s p}=E T_{0} \cdot[1-\exp (-\lambda \cdot L A I)]$

Where $L A I$ is Leaf Area Index [-], and $\lambda$ is a constant and here is 0.5 .

We firstly calculate the daily LAI by fitting a regression curve to the observed LAI (Fig. 5). Then, the reference evapotranspiration $\left(E T_{0}\right)$ was calculated based on the LAI and ground surface coverage fractal. Finally, the $E T_{0}$ was separated into two parts: ground potential evaporation $\left(E_{s p}\right)$ and potential transpiration $\left(T_{p}\right)$ of crop.

(4) Inverse method with PEST

The effective soil hydraulic parameters of the van GenuchtenMualem (VG) model were fitted with the PEST. The initial values of VG model parameters as specified during inverse optimizations are listed in Table 4. Firstly, PEST runs the HYDRUS-1D with an initial guess of the parameters, then compares the model results with observations, adjusts selected parameters using an optimization algorithm and runs the HYDRUS-1D again. The nonlinear parameter estimation of Gauss-Marquardt--Levenberg method (Watermark Computing, 1994) is used for optimization algorithm. The procedure of adjusting selected parameters continues until the difference between the model results and observations or the number of iteration meets a preset criteria. The inverse problem is then to find an optimum combination of parameters that minimizes weighted least square objective function.

The soil water pressure head of eight depths (i.e. 0, 5, 20, 40, 60, 80, 120 , and $160 \mathrm{~cm}$ ) at three growing stages (i.e. before sowing, after irrigation, and after harvesting) has been selected for the objective function. The corresponding weights of observation at each depth were 1,2 , $2,2,2,1,1$, and 1 , respectively. Considering the minor contribution difference of soil at different part on controlling the process of infiltration and evaporation, relative larger weights were put for observations in upper part soil than those in the lower part except for the observation at surface, which has much more variation. After each run of optimization of soil hydraulic parameters, the outputs of soil water pressure head had been used to compare with those outputs with previous soil hydraulic parameters, then the next group of soil hydraulic parameters was adopted according to the

Table 4

The parameters and setting in optimizing process with the PEST.

\begin{tabular}{|c|c|c|c|c|c|c|c|}
\hline $\begin{array}{l}\text { Parameter } \\
\text { name }\end{array}$ & Trans-formation & Change limit & Initial value & Lower bound & Upper bound & Increment type & Increment \\
\hline$\theta_{\mathrm{r}}$ & None & Factor & 0.02 & 0.0001 & 0.2 & Relative & 0.01 \\
\hline$\theta_{\mathrm{s}}$ & None & Factor & 0.40 & 0.30 & 0.57 & Relative & 0.01 \\
\hline$K_{\mathrm{s}}$ & $\log$ & Factor & 35.1 & 1.1 & 1000.0 & Relative & 0.01 \\
\hline$\alpha$ & None & Factor & 0.08 & 0.0001 & 10.0 & Relative & 0.01 \\
\hline $\mathrm{n}$ & None & Factor & 1.50 & 1.0 & 5.0 & Relative & 0.01 \\
\hline
\end{tabular}


Table 5

The statistics of effective hydraulic parameters of 30 equivalent soil columns (scenario 2). ${ }^{\text {a }}$

\begin{tabular}{|c|c|c|c|c|c|}
\hline Statistical parameters & $\begin{array}{l}\text { Residual water content } \\
\theta_{\mathrm{r}}\left(\mathrm{cm}^{3} \mathrm{~cm}^{-3}\right)\end{array}$ & $\begin{array}{l}\text { Saturated water content } \\
\theta_{\mathrm{s}}\left(\mathrm{cm}^{3} \mathrm{~cm}^{-3}\right)\end{array}$ & $\begin{array}{l}\text { Saturated hydraulic } \\
\text { conductivity } \\
K_{\mathrm{s}}\left(\mathrm{cm} \mathrm{d}^{-1}\right)\end{array}$ & $\begin{array}{l}\text { Alpha } \\
\alpha\left(\mathrm{cm}^{-1}\right)\end{array}$ & $\mathrm{n}$ \\
\hline Mean & 0.020 & 0.433 & 35.8173 & 0.0107 & 1.4804 \\
\hline Maximum & 0.055 & 0.549 & 56.9298 & 0.0288 & 1.5320 \\
\hline Minimum & 0.004 & 0.372 & 30.7628 & 0.0048 & 1.3590 \\
\hline Range & 0.051 & 0.177 & 26.1670 & 0.0241 & 0.1730 \\
\hline S.D. & 0.015 & 0.049 & 4.256 & 0.006 & 0.038 \\
\hline C.V. & 0.728 & 0.114 & 0.119 & 0.526 & 0.026 \\
\hline Skewness & 1.132 & 1.048 & 4.369 & 1.529 & -2.065 \\
\hline Kurtosis & 0.494 & 0.336 & 22.527 & 2.282 & 3.921 \\
\hline$K-S^{b}$ & 0.2536 & 0.2021 & 0.0006 & 0.0729 & 0.0059 \\
\hline
\end{tabular}

a The parameters listed in table are the five parameters in van Genuchten model.

b The Kolmogorov-Smirnov test.

optimizing criterion. Considering the optimizing efficiency and the soil pressure head variation.

For the simulation schemes of scenario 1 and scenario 2, we firstly ran the HYDRUS-1D based on the measured soil profiles data to obtain 30 soil water dynamics profiles, and took these profiles as the "fine scale solution". Then took the pressure head values of each soil profiles at eight depths of $0,5,20,40,60,80,120$, and $160 \mathrm{~cm}$ and on three typical days (before sowing, March 15th, 2004; after irrigation, May 25th, 2004; and after harvesting, July 18th, 2004) as input, the effective soil hydraulic parameters of the 30 equivalent soil profiles were optimized by using inverse modeling with PEST software package.

It was assumed in this study that a spatially heterogeneous region can be equivalently represented by an ensemble of individually homogeneous soil. This hypothesis is valid only for areas without significant runoff and with deep groundwater levels (Singh et al., 2006). The application of HYDRUS-1D model in such a distributed manner requires the derivation of all combinations of simulation units at field scale. Subsequently, the outputs of independent soil column runs of HYDRUS-1D are finally synthesized to evaluate the performance of upscaling methods at field scale.
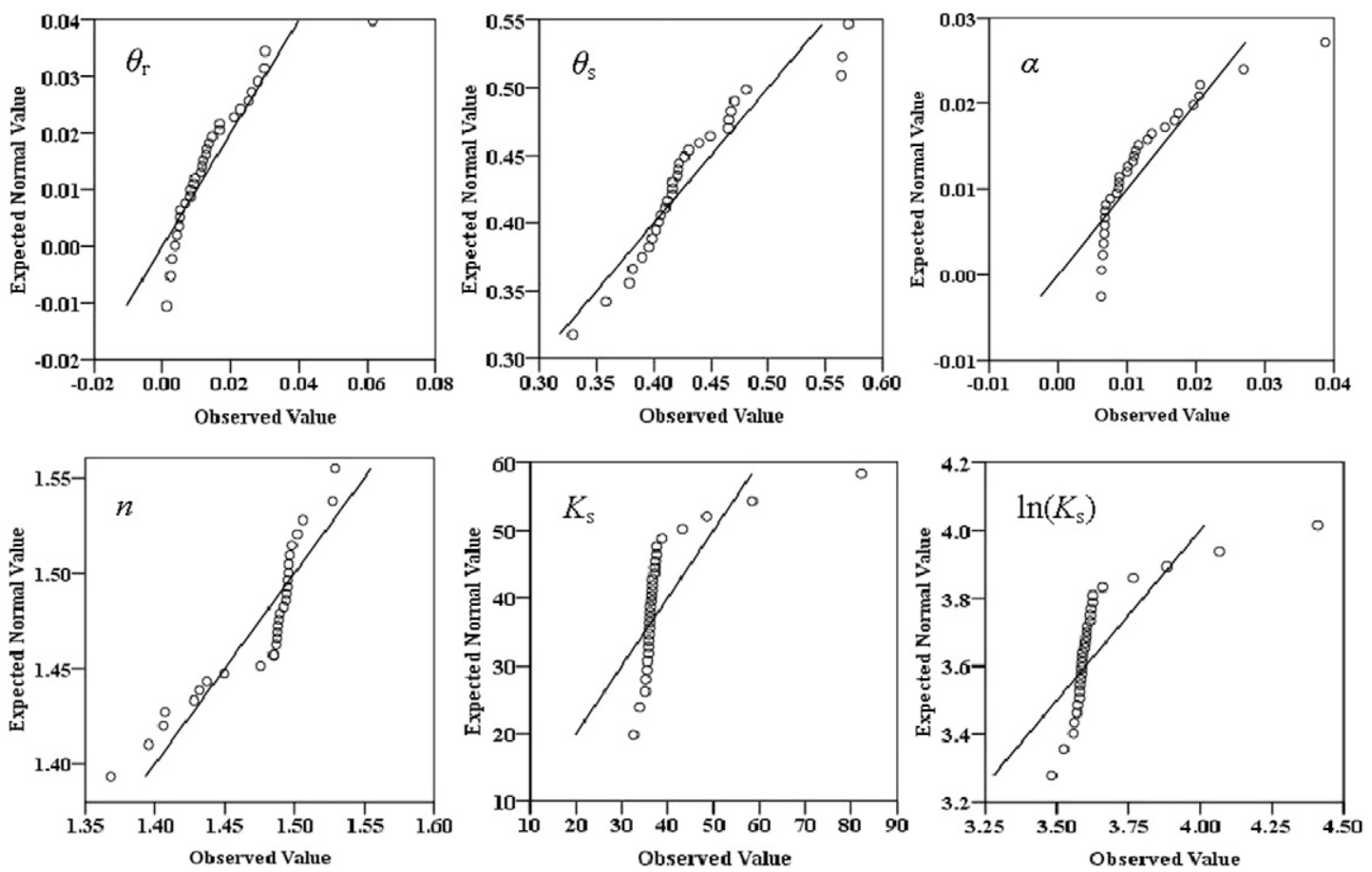

Fig. 6. The Q-Q plots of effective hydraulic parameters of 30 equivalent soil columns. 
Soil water presure head $(-\mathrm{cm})$
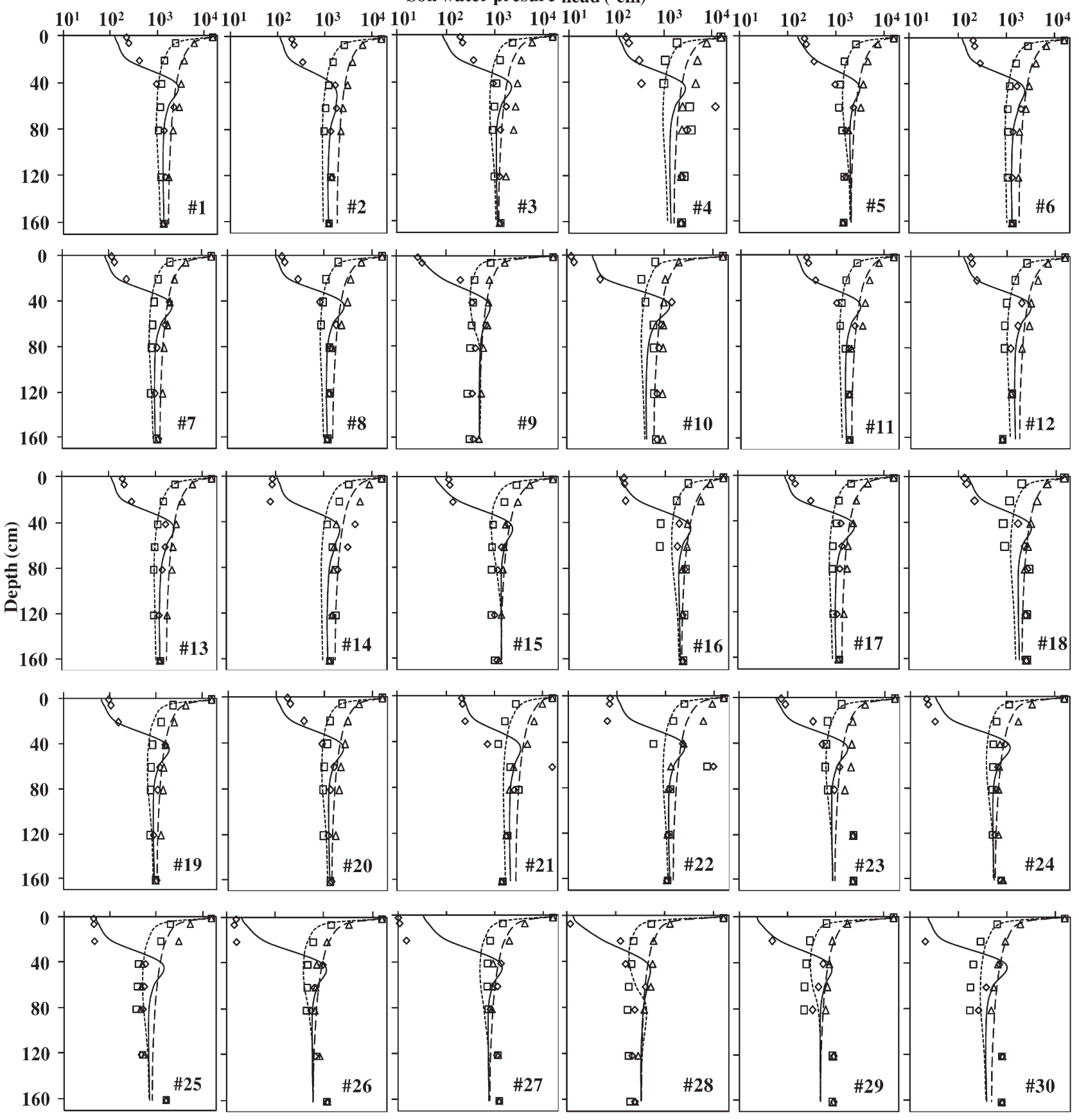

$\Delta$

S1, Mar.15 ---.S2, Mar.15 $\diamond$ S1, May 25

S2, May 25

ㄴ S1, Jul.18

S2, Jul.18

Fig. 7. Comparison of soil water pressure along 30 equivalent soil columns with 'fine scale solution'.

\subsubsection{Performance indicators}

(1) Soil water pressure head along the profiles

The distribution of soil water pressure head along the profiles is mainly governed by the soil hydraulic parameters. Therefore, it was an effective way to evaluate the performance of the upscaling methods by comparing the distribution of soil water pressure head at three specific dates (before sowing, after irrigation event, and after harvest).

\section{(2) Variation of soil water content during the growing stage}

Soil water dynamics during the growing stage was another indicator which was commonly used to evaluate the performance of hydrological models. In addition, as the most important inputs, soil hydraulic parameters undoubtedly play a key role in soil water content simulations. Therefore, the variation of soil water content at three depths (e.g. 5, 40 , and $80 \mathrm{~cm}$ ) during the whole growing stage was selected as an indicator to evaluate the performance of the upscaling approaches.

To evaluate the overall correspondence of model output to the measured values, it is required to quantify the amount by which an estimated value differs from the 'true' value of the quantity being estimated. Such quantification describes how well the estimator describes the 'true' values. In this study, such differences between estimated values and the 'true' values were quantified using the following performance criterion: (i) Root Mean Square Error (RMSE), (ii) Mean Bias Error 
(MBE), and (iii) Mean Relative Error (MRE). The RMSE, MBE and MRE statistics are defined as:

$\mathrm{RMSE}=\sqrt{\frac{\sum\left(P_{i}-O_{i}\right)^{2}}{n}}$

$\mathrm{MBE}=\frac{\sum\left(P_{i}-O_{i}\right)}{n}$

$\mathrm{MRE}=\frac{1}{N} \sum_{i=1}^{N} \frac{\left|P_{i}-O_{i}\right|}{O}$

Where $P_{i}$ is water content predicted by the model in scenario $2, O_{i}$ is the simulated soil water content in scenario 1 , and $n$ is the number of observations. The RMSE and MBE are indicative of error and bias respectively, whereas the MRE gives the bias of the simulated versus observed values.

\section{Results and discussion}

The statistics of the optimized effective soil hydraulic parameters (scenario 2) were listed in Table 5. The mean values of the upscaled van Genuchten parameters in Table 5 are comparable with those in Table 1 (scenario 1), except for the residual water content. Meanwhile, the range and standard variation of the effective soil hydraulic conductivity decreased remarkably. The measured soil hydraulic conductivity showed a strong variation while the variation of the effective soil hydraulic conductivity was moderate.

Quantile-Quantile distribution plot (i.e., Q-Q plot) is generally used to determine whether the distribution of a variable matches a given distribution. If the selected variable matches the test distribution, the points cluster around a straight line. The Q-Q distribution plots of the upscaled effective soil hydraulic parameters were shown in Fig. 6. The $\mathrm{Q}-\mathrm{Q}$ distribution plot showed that the distribution of soil saturated hydraulic conductivity was neither normal nor log-normal. Moreover, the Kolmogorov-Smirnov test showed that the distribution of residual water content $\left(\theta_{\mathrm{r}}\right)$, saturated water content $\left(\theta_{\mathrm{S}}\right)$ and alpha $(\alpha)$ are normal; but the soil saturated hydraulic conductivity $\left(K_{\mathrm{s}}\right)$ and parameter of $\mathrm{n}$ are not normal distribution.

The distribution map of soil water potential head of the 30 soil profiles on three typical days for both simulation scenarios (S1 and S2) were shown in Fig. 7. In general, the simulation result of soil water distribution of the equivalent soil profiles with effective soil hydraulic parameters are fairly good as compared to those of the heterogeneous soil profiles. On each of the three typical days, the soil water potential head of the two scenarios are very similar to each other. Even on the 25th of May (after irrigation), the simulated soil water distribution of most of the equivalent profiles showed fairly agreement with that of the heterogeneous soil profiles, although the soil water potential head along the profile had a large variation. However, for the soil profiles of No. 3, No. 22 and No. 25, the distribution of soil water potential head was quite different with that of the corresponding heterogeneous soil profile for all the three typical days. One common characteristic in these soil profiles was that there is thin clay layer at the depth of $25-80 \mathrm{~cm}$. Just as stated in Erdal et al. (2012), parameter estimation for the layered structure is more difficult compared to the random profile because of the complex structure. The effective hydraulic parameters, consequently, could not be optimized properly.

The results in Table 6 showed that the RMSE for the soil profiles of No. 4, No. 21, No. 22, and No. 23 are relatively high; this was consistent with the presentation of soil pressure head distribution map. The MRE for most soil profiles was less than $30 \%$ and showed a good simulation result. The maximum value of MRE reached $66.0 \%$ and was presented in soil profile of No. 30. As indicated in Sadeghi et al. (2014), the effective hydraulic conductivity function would have a more complex
Table 6

Statistics of simulated soil water distribution of 30 equivalent soil columns and the 'fine scale solution'.

\begin{tabular}{|c|c|c|c|}
\hline Site no. & RMSE & MRE & MBE \\
\hline 1 & 435.20 & 0.20 & 22.73 \\
\hline 2 & 219.11 & 0.14 & 44.75 \\
\hline 3 & 542.75 & 0.26 & 282.24 \\
\hline 4 & 2372.76 & 0.61 & 1073.50 \\
\hline 5 & 552.92 & 0.29 & -261.26 \\
\hline 6 & 208.57 & 0.12 & -16.93 \\
\hline 7 & 115.33 & 0.09 & 15.74 \\
\hline 8 & 425.50 & 0.24 & -19.92 \\
\hline 9 & 134.42 & 0.27 & -57.95 \\
\hline 10 & 210.17 & 0.41 & 77.71 \\
\hline 11 & 546.79 & 0.24 & 56.62 \\
\hline 12 & 416.67 & 0.27 & -163.20 \\
\hline 13 & 195.68 & 0.12 & -27.90 \\
\hline 14 & 940.49 & 0.36 & 403.60 \\
\hline 15 & 303.05 & 0.23 & -140.19 \\
\hline 16 & 486.86 & 0.24 & -26.08 \\
\hline 17 & 233.87 & 0.14 & 5.68 \\
\hline 18 & 646.13 & 0.27 & 166.18 \\
\hline 19 & 181.18 & 0.11 & 79.69 \\
\hline 20 & 318.16 & 0.18 & -18.75 \\
\hline 21 & 2679.39 & 0.49 & 239.47 \\
\hline 22 & 2206.38 & 0.40 & 741.96 \\
\hline 23 & 685.86 & 0.35 & 1305.16 \\
\hline 24 & 235.91 & 0.24 & 89.55 \\
\hline 25 & 690.90 & 0.59 & 116.31 \\
\hline 26 & 251.35 & 0.34 & 91.37 \\
\hline 27 & 282.71 & 0.61 & 158.80 \\
\hline 28 & 112.02 & 0.43 & -46.66 \\
\hline 29 & 206.22 & 0.46 & 40.92 \\
\hline 30 & 208.32 & 0.66 & 32.76 \\
\hline
\end{tabular}

shape than the VG function depending on the orders of the soil layers. The VG function may no longer fit the effective function. So, the inverse modeling in this study (fitting one VG function) to the whole profile would result in some discrepancies. However, it is reasonable to represent a heterogeneous soil profile with a homogeneous one by using the inverse method; at least the soil water distribution in these two scenarios was comparable with each other.

To evaluate the effectiveness of the equivalent soil profiles in another view, we selected the soil water dynamics in the whole growing stage at the depth of $5 \mathrm{~cm}, 40 \mathrm{~cm}$, and $80 \mathrm{~cm}$ as reference, and compared with those values in scenario 2 (Fig. 8). Overall, the soil water dynamics (Fig. 8) in the whole growing stage at all the three different depths for the simulation scenario 1 and scenario 2 were close to each other, and most of the simulation results were similar to each other, even at some of the points such as the maximum, minimum, and inflexion point.

Furthermore, at the depth of $40 \mathrm{~cm}$, most of the simulated soil water dynamics with effective soil hydraulic parameters in scenario 2 showed relatively higher difference as compare to the fine scale solution in scenario 1 (Table 7); while at the depth of $5 \mathrm{~cm}$ and $80 \mathrm{~cm}$, the simulation results of scenario 1 and scenario 2 were comparable for most soil profiles. The strong variation of soil water distribution was probably due to the complex processes (e.g. infiltration, evaporation, transpiration, and so on ) coexisted at the depth of $40 \mathrm{~cm}$. Shafiei et al. (2014) also concluded that different spatial variability of soil hydraulic parameter can lead to quite different simulated soil moisture dynamics and parameter estimation at field scale.

Statistics of actual evaporation $\left(E_{a}\right)$, actual transpiration $\left(T_{a}\right)$, actual evapotranspiration $\left(E T_{a}\right)$ and deep percolation of 30 soil columns during the growing stage of spring wheat was listed in Table 8. The data showed that the $E_{a}, T_{a}, E T_{a}$ and deep percolation of 30 soil columns in scenario 2 were comparable with those in scenario 1 during the whole growing stage. The variation range of $E_{a}$ and $E T_{a}$ in scenario 1 was larger than that in scenario 2 . This may be due to the larger variation of soil hydraulic parameters in scenario 1 . 

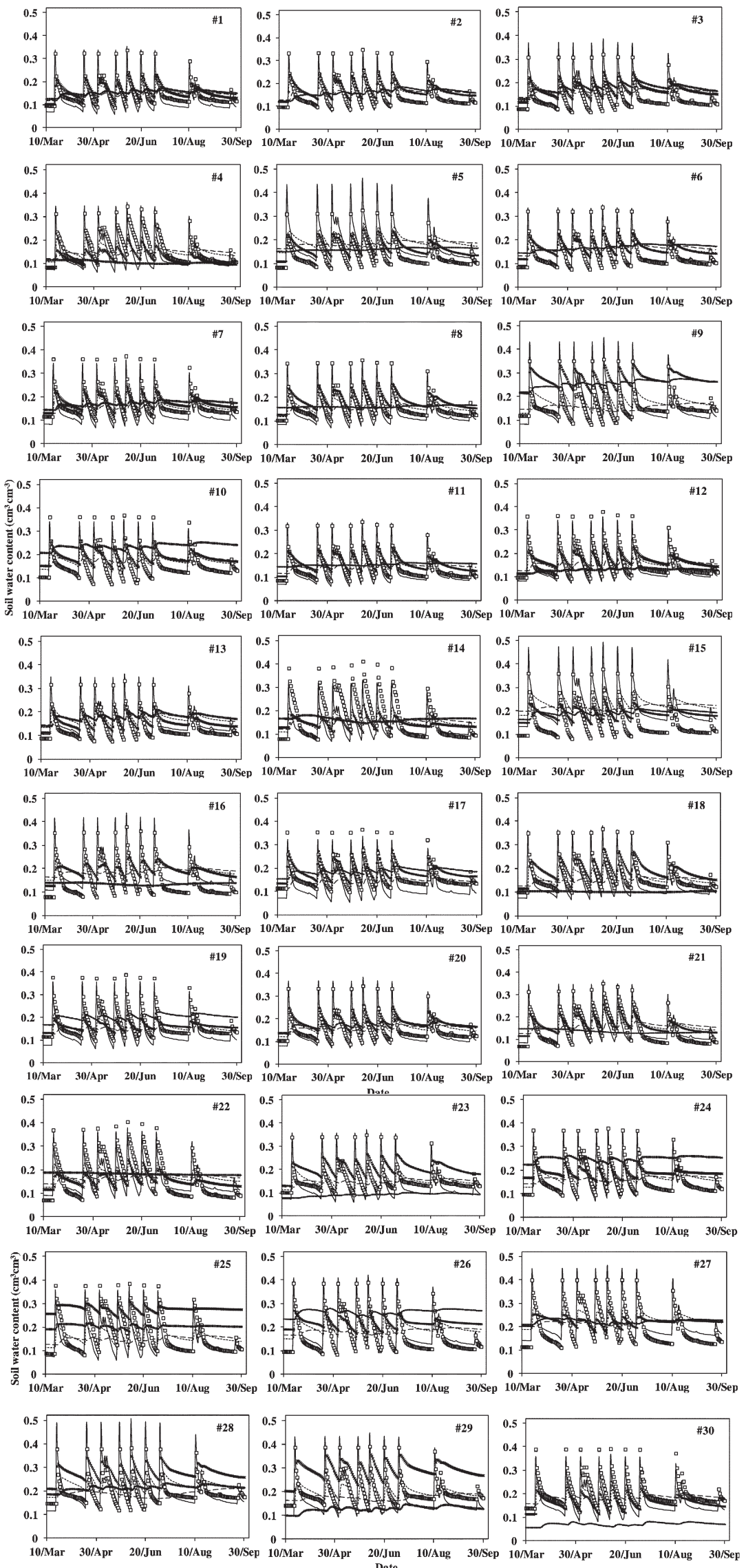

$$
\text { ㅁ } \mathrm{S} 1,5 \mathrm{~cm}-\mathrm{S2,5} \mathrm{cm} \quad \times \mathrm{S} 1,40 \mathrm{~cm} \quad \cdots \cdots+\mathrm{S} 2,40 \mathrm{~cm} \quad+\mathrm{S} 1,80 \mathrm{~cm} \quad--\mathrm{S2,80 \textrm {cm }}
$$

Fig. 8. Comparison of soil water content for 30 equivalent soil columns with 'fine scale solution. 
Table 7

Statistics of soil water flux at different depth of 30 soil columns (after harvesting in 2006).

\begin{tabular}{|c|c|c|c|c|c|c|c|c|}
\hline \multirow[t]{3}{*}{ Depth } & \multicolumn{4}{|l|}{ Scenario 1} & \multicolumn{4}{|l|}{ Scenario 2} \\
\hline & \multirow{2}{*}{$\frac{5 \mathrm{~cm}}{\mathrm{~cm} \mathrm{~d}^{-1}}$} & \multirow[t]{2}{*}{$40 \mathrm{~cm} 80 \mathrm{~cm}$} & & \multirow[t]{2}{*}{$160 \mathrm{~cm}$} & $5 \mathrm{~cm}$ & \multirow[t]{2}{*}{$40 \mathrm{~cm} 80 \mathrm{~cm}$} & & \multirow[t]{2}{*}{$160 \mathrm{~cm}$} \\
\hline & & & & & $\mathrm{cm} \mathrm{d}^{-1}$ & & & \\
\hline Mean & 0.10355 & 0.03386 & -0.00549 & -0.00253 & 0.08456 & 0.02451 & -0.01824 & -0.00468 \\
\hline Max. & 0.18340 & 0.09708 & 0.03900 & -0.00001 & 0.10700 & 0.05255 & 0.00111 & -0.00116 \\
\hline Min. & 0.03148 & -0.03643 & -0.05943 & -0.03329 & 0.06602 & -0.02813 & -0.03051 & -0.01109 \\
\hline Range & 0.15192 & 0.13351 & 0.09843 & 0.03328 & 0.04098 & 0.08068 & 0.03162 & 0.00993 \\
\hline S. D. & 0.0370 & 0.0311 & 0.0156 & 0.0063 & 0.0110 & 0.0203 & 0.0096 & 0.0026 \\
\hline Skew & -0.0307 & -0.3377 & -0.7090 & -4.3677 & -0.1045 & -0.7431 & 0.5597 & -0.8815 \\
\hline Kurtosis & -0.5939 & -0.4187 & 5.8632 & 21.1574 & -1.0643 & 0.2491 & -1.0107 & 0.0682 \\
\hline $\mathrm{K}-\mathrm{S}^{\mathrm{a}}$ & 0.9202 & 0.4617 & 0.5421 & 0.0016 & 0.5998 & 0.9070 & 0.6492 & 0.5904 \\
\hline
\end{tabular}

a The Kolmogorov-Smirnov test.

Table 8

Statistics of $E_{a}, T_{a}, E T_{a}$ and percolation in 30 soil columns at the growing stage of spring wheat.

\begin{tabular}{|c|c|c|c|c|c|c|c|c|}
\hline & \multicolumn{4}{|c|}{ Scenario 1} & \multicolumn{4}{|c|}{ Scenario 2} \\
\hline & $E_{a}$ & \multirow[t]{2}{*}{$T_{a}$} & \multirow[t]{2}{*}{$E T_{a}$} & \multirow[t]{2}{*}{ Percolation } & $E_{a}$ & \multirow[t]{2}{*}{$T_{a}$} & \multirow[t]{2}{*}{$E T_{a}$} & \multirow[t]{2}{*}{ Percolation } \\
\hline & $\mathrm{cm}$ & & & & $\mathrm{cm}$ & & & \\
\hline Mean & 15.88 & 36.51 & 52.39 & -0.249 & 14.94 & 36.44 & 51.38 & -0.344 \\
\hline Max. & 20.91 & 38.19 & 56.25 & -0.002 & 16.3 & 38.5 & 53.58 & -0.138 \\
\hline Min. & 10.6 & 34.77 & 48.17 & -2.896 & 13.27 & 33.91 & 49.87 & -0.831 \\
\hline Range & 10.31 & 3.42 & 8.08 & 2.894 & 3.03 & 4.59 & 3.71 & 0.693 \\
\hline S. D. & 2.542 & 1.001 & 1.983 & 0.567 & 0.668 & 1.208 & 1.004 & 0.147 \\
\hline CV & 0.160 & 0.027 & 0.038 & 2.275 & 0.045 & 0.033 & 0.020 & 0.428 \\
\hline Skew. & 0.077 & 0.220 & 0.164 & -3.874 & -0.377 & 0.105 & 0.536 & -1.645 \\
\hline Kurtosis & 0.129 & -1.068 & -0.245 & 17.049 & 1.406 & -0.933 & -0.478 & 4.053 \\
\hline $\mathrm{K}-\mathrm{S}^{\mathrm{a}}$ & 0.850 & 0.563 & 0.948 & 0.003 & 0.459 & 0.613 & 0.899 & 0.394 \\
\hline
\end{tabular}

a The Kolmogorov-Smirnov test.

Based on the effective hydraulic parameters of the equivalent soil profiles obtained in scenario 2, we further upscaled the soil hydraulic parameters of the 30 soil profiles to a larger area by separately using the Inverse modeling (scenario 3) and Block-Kriging (scenario 4) method, and finally obtained the effective hydraulic parameters of an upscaled equivalent soil column, respectively.

The obtained effective hydraulic parameters (mean values for scenario 1 and scenario 2 ) of the four scenarios were listed in Table 9. The data showed that mean value of residual soil water content in scenario 1 was higher than that in other three scenarios, while the soil saturated hydraulic conductivity was smaller in scenario 1 than that in other three scenarios. Overall, the soil hydraulic parameters for all the four scenarios were close to each other, and the mean values of the effective soil hydraulic parameters in scenario 2 was more closer to the values in scenario 4 .

Soil water pressure head along two equivalent soil columns (S3 and S4) and the range of corresponding "fine scale solution" (S1) at three typical time were showed in Fig. 9. In general, the simulation results of different scenarios (S3 and S4) were comparable with each other; the soil water pressure from both of them was close to the median for the scenario 1 (S1). In addition, the dynamics of soil water content of the two equivalent soil columns (S3 and S4) during the growing stage in the year of 2006 was showed in Fig. 10. Although the difference at the depth of $40 \mathrm{~cm}$ was significant, the soil water content for the scenario 3 and scenario 4 always showed similar variation trend during the growing stage in 2006. It indicated that the two upscaling approaches showed similar effects in determining the effective hydraulic parameters. In another word, both of the soil bodies which respectively obtained through the inverse modeling and block Kriging were equivalent to the fine scale solution.

The soil water flux at different depths of the four simulation scenarios and the water balance component of the four simulation scenarios were listed in Tables 10 and 11, respectively. Although the soil water flux for scenario 2 were most closest to those in scenario 3. There was no notable difference in water balance components between the scenarios. It further confirmed the finding that both of the soil bodies which respectively obtained through the inverse modeling and block Kriging were equivalent to the fine scale solution.

Moreover, the five parameters in VG model for each soil layer of the 30 soil columns were compared with the corresponding effective values of the VG parameters in other two scenarios (S3 and S4) (Fig. 11). For all the 30 soil columns in scenario 1 , the median of $K_{\mathrm{s}}$ values in the first layer, as compared to that in other soil layers, was most closest to the effective $K_{\mathrm{s}}$ values for other three scenarios; and the effective $K_{\mathrm{s}}$ values

Table 9

Soil effective hydraulic parameters with 'fine scale solution'.

\begin{tabular}{|c|c|c|c|c|c|}
\hline & $\begin{array}{l}\text { Residual water content } \\
\theta_{\mathrm{r}}\left(\mathrm{cm}^{3} \mathrm{~cm}^{-3}\right)\end{array}$ & $\begin{array}{l}\text { Saturated water content } \\
\theta_{\mathrm{s}}\left(\mathrm{cm}^{3} \mathrm{~cm}^{-3}\right)\end{array}$ & $\begin{array}{l}\alpha \\
\left(\mathrm{cm}^{-1}\right)\end{array}$ & $\begin{array}{l}\mathrm{n} \\
-\end{array}$ & $\begin{array}{l}\text { Saturated hydraulic conductivity } \\
K_{\mathrm{s}}\left(\mathrm{cm} \mathrm{d}^{-1}\right)\end{array}$ \\
\hline Scenario 1 (mean) & 0.0563 & 0.4181 & 0.0130 & 1.5950 & 34.0171 \\
\hline Scenario 2 (mean) & 0.0151 & 0.4320 & 0.0123 & 1.4738 & 39.1131 \\
\hline Scenario 3 & 0.0126 & 0.3893 & 0.0095 & 1.4839 & 37.1186 \\
\hline Scenario 4 & 0.0143 & 0.4328 & 0.0117 & 1.4719 & 39.6722 \\
\hline
\end{tabular}



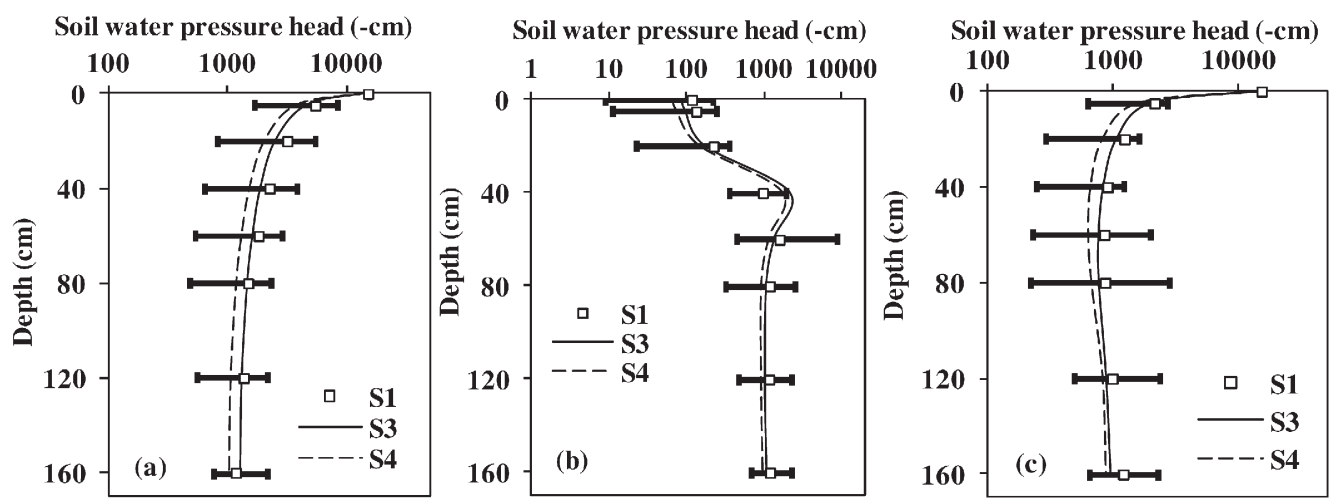

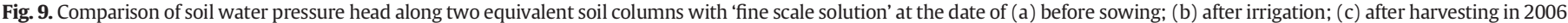
(the square at each depth was the median of 30 soil profiles; the error bar was the $10 \%$ and $90 \%$ percentile, respectively).

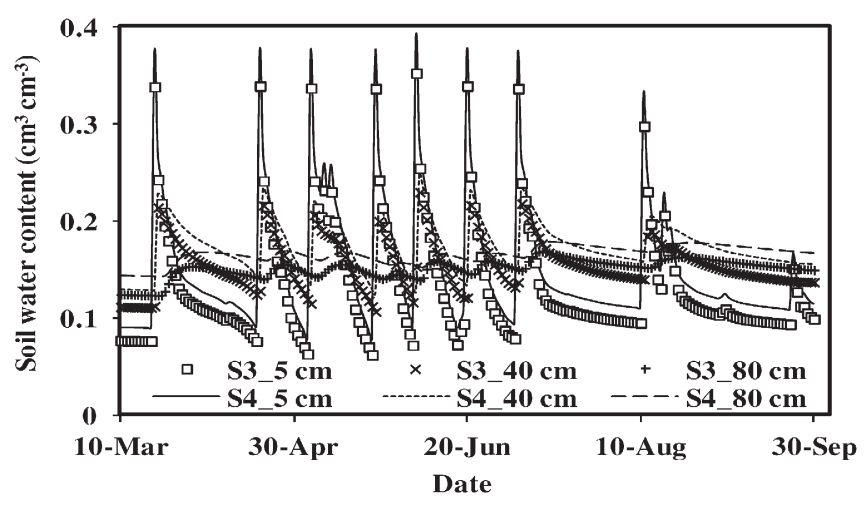

Fig. 10. Comparison of dynamic soil water content of the two equivalent soil columns during the growing stage of spring wheat.

Table 10

Soil water flux at four different depths for the four simulation scenarios (after harvesting in 2006).

\begin{tabular}{lllll}
\hline & \multicolumn{3}{l}{ Water flux } & \\
\cline { 2 - 5 } & $\frac{5 \mathrm{~cm}}{\mathrm{~cm} \mathrm{~d}^{-1}}$ & $40 \mathrm{~cm}$ & $80 \mathrm{~cm}$ & $160 \mathrm{~cm}$ \\
& & & & \\
\hline Scenario 1 (mean) & 0.10355 & 0.03386 & -0.00549 & -0.00253 \\
Scenario 2 (mean) & 0.08456 & 0.02451 & -0.01824 & -0.00468 \\
Scenario 3 & 0.08528 & 0.03135 & -0.01966 & -0.00454 \\
Scenario 4 & 0.07963 & 0.01752 & -0.02712 & -0.00306 \\
\hline
\end{tabular}

for those three scenarios were also close to each other. The distribution of $\theta_{\mathrm{s}}$ values showed a rather broad range among the eight soil layers, the median of $\theta_{\mathrm{s}}$ values for the top three layers were close to the effective $\theta_{\mathrm{s}}$ values of scenario 2 and scenario 3 , but fairly smaller than that of scenario 4.
On the contrary, the distribution of $\theta_{\mathrm{r}}$ values was quite different from that of $K_{\mathrm{s}}$ and $\theta_{\mathrm{s}}$. The median of $\theta_{\mathrm{r}}$ values of all the eight soil layers in scenario 1 was much greater than the effective $\theta_{\mathrm{r}}$ value of other three scenarios; while the median of effective $\theta_{\mathrm{r}}$ value of scenario 2 , the effective $\theta_{\mathrm{r}}$ value of scenario 3 and scenario 4 was close to each other. In another word, it was difficult to use $\theta_{\mathrm{r}}$ data of any layer of the 30 soil columns to represent the whole soil column. For the parameter of $n$ and alpha, the medians for the eight soil layers of all the 30 soil columns in scenario 1 showed little variation and were comparable to the median of effective $\theta_{\mathrm{r}}$ value of scenario 2 , and to the effective $\theta_{\mathrm{r}}$ value of scenario 3 and that of scenario 4.

However, as the results in Table 12 indicated, the water pressure head, soil water content, and the evaporation showed little variation while the residual soil water content gradually increased. The soil water content showed larger relative error than that of evaporation, but all of them were within the range of $\pm 20 \%$. The relative error of evaporation was less than $2 \%$ even the residual soil water content was tripled. In another word, the soil water dynamics is not sensitive to residual soil water content. The performance of the effective VG parameters generated by using the three inverse modeling approaches was reliable, even if the generated residual water content was not stable.

\section{Conclusions}

The feasibility and validity of the three inverse modeling approaches were investigated and tested based on one-dimensional numerical modeling of the soil water dynamics process. We confirm that there are no unique effective average properties for a heterogeneous field that give the best field average soil water content profiles for both infiltration and redistribution. Although, the parameter estimation for the layered structure is more difficult due to the structure complexity, it is feasible to use the PEST model combined with the HYDRUS-1D to inversely determine the effective hydraulic parameters of the equivalent soil profile. The results of the upscaling procedure showed that the inverse modeling approach performed well in simulating the soil water distribution and/or dynamics, but still needs to be improved for

Table 11

Water balance component for the four simulation scenarios (after harvesting in 2006).

\begin{tabular}{|c|c|c|c|c|c|c|}
\hline \multirow[t]{2}{*}{ Simulation scheme } & $T_{a}$ & $E_{a}$ & Percolation & Infiltration & Storage change & Absolute error \\
\hline & \multicolumn{6}{|l|}{$\mathrm{cm}$} \\
\hline Scenario 1 (mean) & 35.03 & 15.52 & 0.477 & 56.98 & 4.546 & 0.908 \\
\hline Scenario 2 (mean) & 34.98 & 16.49 & 0.251 & 56.98 & 4.458 & 0.930 \\
\hline Scenario 3 & 36.61 & 14.58 & 0.374 & 56.98 & 5.647 & 0.925 \\
\hline Scenario 4 & 37.27 & 14.76 & 0.296 & 56.98 & 4.913 & 1.310 \\
\hline
\end{tabular}



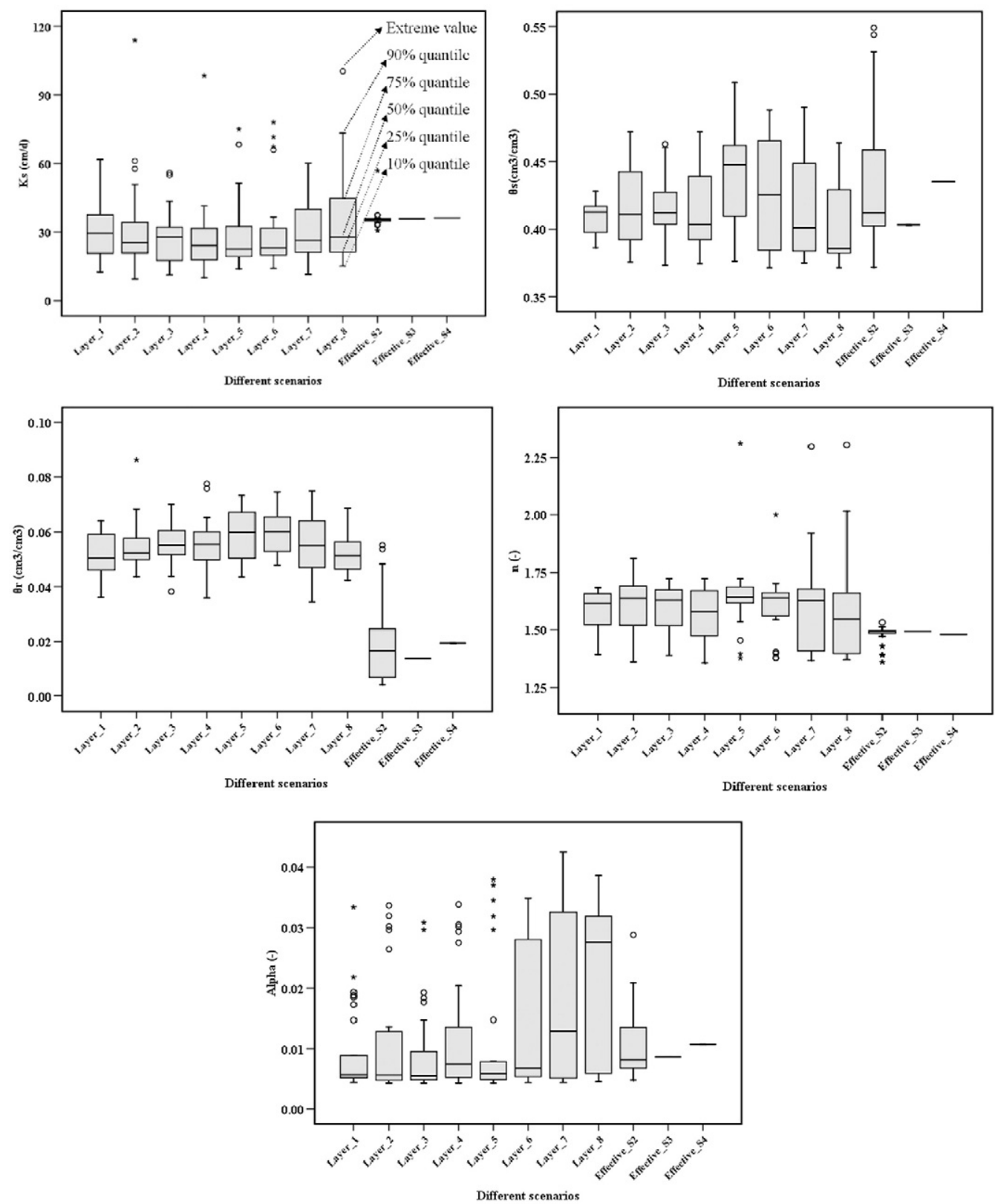

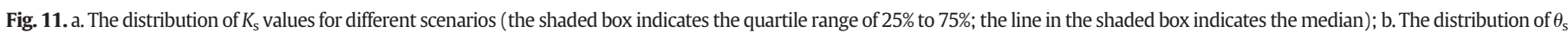

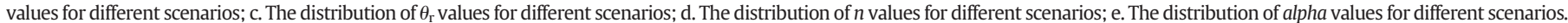

layered soils, especially with fine-textured soil layer. In another words, Inverse modeling method discussed in present study can be a useful approach when an effective model is sought for a larger scale than the observation.

\section{Acknowledgments}

This research was sponsored by the Chinese National Natural Science Fund (Grant No. 51321001, No. 51279203 and No. 51039007).

Table 12

The uncertainty effect of residual soil water content $\left(\theta_{\mathrm{r}}\right)$ on soil water dynamics.

\begin{tabular}{|c|c|c|c|c|c|c|c|c|}
\hline \multirow{2}{*}{ Residual soil water content $\left(\theta_{\mathrm{r}}\right)$} & $-75 \%$ & $-50 \%$ & $-25 \%$ & & $+25 \%$ & $+50 \%$ & $+100 \%$ & $+200 \%$ \\
\hline & 0.0034 & 0.0069 & 0.0103 & 0.0137 & 0.0171 & 0.0205 & 0.0274 & 0.0411 \\
\hline Water pressure head $(\mathrm{cm})$ & -2006.92 & -2004.13 & -2005.02 & -2004.51 & -2003.72 & -2005.02 & -1998.25 & -1998.82 \\
\hline Relative error (\%) & 0.12 & -0.02 & 0.02 & 0.00 & -0.04 & 0.03 & -0.31 & -0.28 \\
\hline Soil water content (\%) & 0.1011 & 0.1038 & 0.1063 & 0.1089 & 0.1115 & 0.1141 & 0.1194 & 0.1297 \\
\hline Relative error (\%) & -7.16 & -4.68 & -2.39 & 0.00 & 2.39 & 4.78 & 9.64 & 19.10 \\
\hline Evaporation (cm) & 14.86 & 14.83 & 14.81 & 14.78 & 14.75 & 14.72 & 14.67 & 14.54 \\
\hline Relative error (\%) & 0.54 & 0.34 & 0.20 & 0.00 & -0.20 & -0.41 & -0.74 & -1.62 \\
\hline
\end{tabular}




\section{References}

Ahuja, L.R., Ma, L., Green, T.R., 2010. Effective soil properties of heterogeneous areas for modeling infiltration and redistribution. Soil Sci. Soc. Am. J. 74 (5), 1469-1482.

Allen, R.G., Pereira, L.S., Raes, D., Smith, M., 1998. Crop evapotranspiration. Guidelines for computing crop water requirements. FAO Irrigation and Drainage Paper 56. Food and Agriculture Organization of the United Nations, Rome, Italy (300 pp.).

Arya, L.M., Heitman, J.L., 2010. Hydraulic conductivity function from water flow similarity in idealized-and natural-structure pores. Soil Sci. Soc. Am. J. 74 (3), 787-796.

Belmans, C., Wesseling, J.G., Feddes, R.A., 1983. Simulation of the water balance of a cropped soil: SWATRE. J. Hydrol. 63, 271-286.

Braud, I., Varado, N., Olioso, A., 2005. Comparison of root water uptake modules using either the surface energy balance or potential transpiration. Journal of Hydrology 301 (1), 267-286.

Chrysikopoulos, C.V., 1995. Effective parameters for flow in saturated heterogeneous porous media. J. Hydrol. 170, 181-197.

Corwin, D.L., Hopmans, J., de Rooij, G.H., 2006. From field- to landscape-scale vadose zone processes: scale issues, modeling, and monitoring. Vadose Zone J. 5, 129-139.

Desbarats, A.J., 1998. Scaling of constitutive relationships in unsaturated heterogeneous media: a numerical investigation. Water Resour. Res. 34, 1427-1435.

Erdal, D., Neuweiler, I., Huisman, J.A., 2012. Estimating effective model parameters for heterogeneous unsaturated flow using error models for bias correction. Water Resour. Res. 48, w06530.

Feddes, R.A., Kowalik, P.J., Zaradny, H., 1978. Simulation of Field Water use and Crop Yield John Wiley \& Sons, New York.

Feddes, R.A., Rooij, G.H.D., Dam, J.C.V., Kabat, P., Ogers, P., Stricker, J.N.M., 1993. Estimation of regional effective soil hydraulic parameters by inverse modeling (Advanced) pp. 211-231.

Guber, A.K., Pachepsky, Y.A., van Genuchten, M.T., Rawls, W.J., Simunek, J., Jacques, D., Nicholson, T.J., Cady, R.E., 2006. Field-scale water flow simulations using ensembles of pedotransfer functions for soil water retention. Vadose Zone J. 5, 234-247.

Gee, G.W., Bauder, J.W., 1986. Particle-size analysis. In: Klute, A. (Ed.), Methods of Soil Analysis. Part 1, 2nd ed. SSSA Book Series 5. SSSA, Madison, WI, pp. 383-411.

Hughson, D.L., Yeh, T.-C.J., 2000. An inverse model for three-dimensional flow in variably saturated porous media. Water Resour. Res. 36 (4), 829-839.

Huygen, J., Van Dam, J.C., Kroes, J.G., Wesseling, J.G., 1997. SWAP 2.0: input and output manual. Wageningen Agricultural University, and DLO-Staring Centrum, Wageningen $52 \mathrm{pp}$.

Jhorar, R.K., Bastiaanssen, W.G.M., Feddes, R.A., Van Dam, J.C., 2002. Inversely estimating soil hydraulic functions using evapotranspiration fluxes. J. Hydrol. 258 (1-4) 198-213.

Khaleel, R., Yeh, T.C.J., Lu, Z.M., 2002. Upscaled flow and transport properties for heterogeneous unsaturated media. Water Resour. Res. 38 (5), 1053. http://dx.doi.org/10.1029/ 2000 WR000072.

Klute, A., Dirksen, C., 1986. Hydraulic conductivity and diffusivity: laboratory methods. In: Klute, A. (Ed.), Methods of Soil Analysis. Part 1, 2nd ed. Agron. Monogr. 9. ASA and SSSA, Madison, WI, pp. 687-734.

Kosugi, K., 1996. Lognormal distribution model for unsaturated soil hydraulic properties. Water Resour. Res. 32, 2697-2703.

Bureau, M.W.C., 1996. The ninth five-year water-saving Irrigation Planning of Minqin county, Gansu province. Technical Report, Minqin Water Conservancy Bureau, Minqin, Gansu (In Chinese).

Liu, Y., Pereira, L.S., Teixeira, J.L., 1997. Update definition and computation of reference evapotranspiration comparison with former method. Journal of Hydraulic Engineering 6, 27-33.

Mohanty, B.P., 2013. Soil hydraulic property estimation using remote sensing: a review. Vadose Zone J. http://dx.doi.org/10.2136/vzj2013.06.0100.
Priesack, E., Durner, W., 2006. Closed form expression for the multi-modal unsaturated conductivity function. Vadose Zone J. 5, 121-124.

Rucker, D.F., 2010. Inverse upscaling of hydraulic parameters during constant flux infiltration using borehole radar. Adv. Water Resour. http://dx.doi.org/10.1016/j. advwatres. 2010.11.001.

Sadeghi, M., Tuller, M., Gohardoust, M.R., Jones, S.B., 2014. Column-scale unsaturated hydraulic conductivity estimates in coarse-textured homogeneous and layered soils derived under steady-state evaporation from a water table. J. Hydrol. 519, 1238-1248http://dx.doi.org/10.1016/j.jhydrol.2014.09.004.

Schaap, M.G., 1999. Rosetta (Ver. 1.1). U.S. Salinity Laboratory, ARS-USDA (Copyright).

Schaap, M.G., Leij, F.J., 2000. Improved prediction of unsaturated hydraulic conductivity with the Mualem-van Genuchten model. Soil Sci. Soc. Am. J. 64, 843-851.

Shafiei, M., Ghahraman, B., Saghafian, B., Davary, K., Pande, S., Vazifedoust, M., 2014. Uncertainty assessment of the agro-hydrological SWAP model application at field scale: a case study in a dry region. Agric. Water Manag. 146, 324-334.

Šimůnek, J., Šejna, M., van Genuchten, M.T., 1998. The HYDRUS-1D software package for simulating one-dimensional movement of water, heat, and multiple solutes in variably saturated media. Version 1.0. IGWMCTPS-70. Int. Ground Water Model. Ctr., Colorado School of Mines, Golden.

Singh, R., Kroes, J.G., Van Dam, J.C., Feddes, R.A., 2006. Distributed ecohydrological modelling to evaluate the performance of irrigation system in Sirsa district, India: I. Current water management and its productivity. J. Hydrol. 329 (3), 692-713.

Sommer, R., Folster, H., Vielhauer, K., Carvalho, E.J.M., Vlek, P.L.G., 2003. Deep soil water dynamics and depletion by secondary vegetation in the Eastern Amazon. Soil Sci. Soc. Am. J. 67, 1672-1686.

Szymkiewicz, A., Helmig, R., Neuweiler, I., 2012. Upscaling unsaturated flow in binary porous media with air entry pressure effects. Water Resour. Res. 48, W04522. http://dx. doi.org/10.1029/2011WR010893.

Watermark Computing, 1994. PEST: model independent parameter estimation. Watermark Computing, Brisbane, Australia.

Vachaud, G., Dane, J.H., 2002. Instantaneous profile. In: Dane, J.H., Topp, G.C. (Eds.), Methods of Soil Analysis. Part 4. Physical MethodsSSSA Book Ser. 5. SSSA, Madison, WI, pp. 937-945.

Van Genuchten, M.T., 1980. A closed-form equation for predicting the hydraulic conductivity of unsaturated soils. Soil Sci. Soc. Am. J. 44 (5), 892-898.

Vereecken, H., Kasteel, R., Vanderborght, J., Harter, T., 2007. Upscaling hydraulic properties and soil water flow processes in heterogeneous soils: a review. Vadose Zone J. $6,1-28$.

Vogel, H.-J., Weller, U., Ippisch, O., 2010. Non-equilibrium in soil hydraulic modeling. J. Hydrol. http://dx.doi.org/10.1016/j.jhydrol.2010.03.018.

Vrugt, J.A., Stauffer, P.H., Wohling, T., Robinson, B.A., Vesselinov, V.V., 2008. Inverse modeling of subsurface flow and transport properties: a review with new developments. Vadose Zone J. 7, 843-864.

Wesseling, J.G., 1991. Meerjarige simulaties van grondwaterontrekking voor verschillende bodemprofielen, groundwatertrappen en gewassen met het model SWATRE, Rep. 152. Winand Staring Cent., Wageningen, Netherlands.

Yeh, T.-C.J., 1998. Scale issues of heterogeneity in vadose zone hydrology. In: Sposito, G. (Ed.), Scale Dependence and Scale Invariance. Cambridge Univ. Press, New York.

Zhang, R.D., 2004. Applied Geostatistics in Environmental Science. Science Press USA Inc., North Brunswick

Zhu, J., 2008. Equivalent parallel and perpendicular unsaturated hydraulic conductivities: arithmetic mean or harmonic mean? Soil Sci. Soc. Am. J. 72, 1226-1233.

Zhu, J., Mohanty, B.P., 2003. Effective hydraulic parameters for steady state flows in heterogeneous soils. Water Resour. Res. 39 (8), 1227. http://dx.doi.org/10.1029/ 2002WR001831. 